Research Article

\title{
Modeling the Impacts of Venture Capital Investment on Firm Innovation
}

\author{
Han Qiao, ${ }^{1}$ Sen Zhang, ${ }^{1}$ and Yao Xiao $\mathbb{D}^{2,3}$ \\ ${ }^{1}$ School of Economics, Henan University, Kaifeng 475004, China \\ ${ }^{2}$ School of Economics and Resource Management, Beijing Normal University, Beijing 100875, China \\ ${ }^{3}$ Center for Innovation and Development Studies, Beijing Normal University, Zhuhai 519000, China \\ Correspondence should be addressed to Yao Xiao; xiaoyao@bnu.edu.cn
}

Received 8 May 2021; Accepted 29 June 2021; Published 7 July 2021

Academic Editor: Daqing Gong

Copyright (C) 2021 Han Qiao et al. This is an open access article distributed under the Creative Commons Attribution License, which permits unrestricted use, distribution, and reproduction in any medium, provided the original work is properly cited.

Taking firms listed on the Chinese Growth Enterprise Market (GEM) in 2008-2017 as the sample, this study investigates the impact of venture capital (VC) investment on Chinese firm innovation using propensity score matching and a difference-indifferences (PSM-DID) model. The results show that, overall, firms' innovation inputs and outputs do not show obvious enhancement due to VC entry, but instead show a strong and then weak inhibitory effect. VCs have heterogeneous impacts on firm innovation; that is, compared to other types of firms, firms with technology-dependent characteristics and firms whose actual controllers are experts in the same industry can effectively mitigate the adverse impact of VC on innovation inputs and gradually promote growth in the quantity and quality of the innovation outputs after the second year of VC entry. This study not only reveals the impact of VC on firm innovation activities in the Chinese capital market but also provides empirical evidence to help improve the financial innovation service system and the use of the capital market to promote innovation in China.

\section{Introduction}

Innovation is the core driving force of economic and social development. As innovation agents at the micro level, firms show significant positive externalities in their innovation outcomes [1]. However, their innovation activities are exposed to high risks due to characteristics such as high investment, long cycles, and low success rates. Therefore, governments worldwide generally formulate multiple policies to support firm innovation $[2,3]$. According to a report published by Eurostat in 2009, government subsidies accounted for $30 \%$ of innovation and research and development (R\&D) investment in the U.S., 35\% in the European Union, and $18.5 \%$ in Japan during 1995-2005 [4]. The government of China, as an emerging economy, also developed a policy system to support innovation in small- and medium-sized enterprises (SMEs). In addition to innovation policies such as R\&D investment subsidies and tax incentives aimed directly at firms, the Chinese government introduced policies related to supporting the development of venture capital institutions and investment (VC) in recent years. With these policies, the Chinese government hopes to leverage the ability of VCs to identify potential firms as well as its advantages in financing, intelligence, and resources to drive firm innovation through market-based allocation of social capital. With the support of relevant policies, especially the establishment of the Chinese Growth Enterprise Market (GEM), the scale of China's VC market expanded rapidly in recent years. According to Crunchbase (an industry consultancy), China's total VC investment reached USD 93.8 billion in 2018, surpassing the U.S. to rank first in the world. Has VC played a positive role in supporting firm innovation as policymakers expected in Chinese market? Considering that the institutional environment for the development of VCs in China differs from that in the European and U.S. capital markets, the study of the topic above has important theoretical and practical significance for revealing the innovation driving effect of Chinese capital market represented by venture capital and further improving financial innovation service system. 
For a long time, the relationship between VCs and innovation has not been systematically tested, and it has been assumed empirically that VCs promote firm innovation [5]. However, empirical studies on national capital markets since the 21 st century showed that VCs do not always promote firm innovation. There is no consensus in the academic community on the effects of VCs on innovation [6]. Most prior studies found that VCs raise the innovation level of their portfolio firms [7-12] through three mechanisms. First, VCs promote the innovation level of its portfolio firms by providing innovation funds [7] and industry resources $[11,13,14]$. Second, VCs usually have a keen business sense and foresight [15-17] and can provide firms with management experience and strategic guidance [18-20]. Through ratchet terms, preferential subscriptions, and the assignment of board members, VCs can set up a supervision and restraint mechanism to optimize the corporate governance structure and supervise the implementation of strategic guidance, thus reducing agency problems and improving the efficiency of firm innovation $[15,16,21]$. Third, the capital injection behavior of highly reputable VCs can release positive signals to the market, core employees of portfolio firms, and potential customers and partners and raise firms' recognition and certain expectation for future development, which indirectly provides conditions for firm innovation $[13,22]$. In addition, related studies also examine factors mediating the effects of VCs on firm innovation from various aspects, such as the type of VC $[23,24]$, the duration of the fund $[25,26]$, the timing of investment and exit $[27,28]$, the number of joint VC participations $[29,30]$, the amount of capital injected [31], and the choice of exit method $[21,28]$. However, some studies also found that VCs have an insignificant effect on innovation [32], and even reduce the innovation level of firms in general [12, 33, 34]. For example, the short-term profit-seeking goals of VCs may conflict with the long-term innovation-driven strategies of firms [20], leading to the forced departure of entrepreneurs from the firms they created [16], dilution of the entrepreneurs' shares, and the sale or direct channeling of innovative ideas of firms to affiliates $[22,35,36]$. In this manner, VCs can inhibit the innovative behavior of its portfolio firms. In addition, to realize returns on investment as quickly as possible, VCs may focus more on commercializing existing technologies after entering the firms; they can also help firms expand rapidly, crowd out competitors, and create monopolies, thus ultimately hindering innovation [37].

A review of the literature reveals controversial findings on the effects of VCs on innovation. One major reason is the difference in sample selection; that is, the different impacts of VCs on firm innovation can arise from the heterogeneous environments that serve as data sources [6, 38]. Existing studies focused mostly on VCs in European countries and the U.S., and less on the relationship between VCs and firm innovation in emerging capital markets such as China. The institutional environment for the development of VCs in China differs from that in the European and U.S. capital markets, so the findings of existing studies are not suitable to explain the practices in China. For these considerations, this study selected data on VCs and the innovation activities of
Chinese GEM-listed firms from 2008 to 2017 to explore the impact of VCs on firm innovation in the Chinese capital market from the firms' perspective.

Compared to the existing literature, this study offers three main contributions. Prior studies examine mainly the impact of VCs on innovation outputs. In this study, we included both innovation inputs and outputs in the research framework for a comparative study to examine the differences in the impact of VC entry on both. Second, most prior studies take a VC perspective to examine its impact on firm innovation. However, we found from an in-depth investigation into the data that more than half of the portfolio firms in the Chinese capital market witness the entry and exit of multiple VC investments during the period from initial financing to listing, making it difficult to measure the characteristics of the VC institutions investing in portfolio firms. Additionally, research on innovation effects from a VC perspective ignores the main position of firms in their innovation activities to some extent. Some firms have special demand for innovation, which may have heterogeneous effects on the impact of VCs on innovation. For this consideration, we further explained the different effects of VCs on firm innovation from the perspective of firms' technology preference. Third, to alleviate the endogeneity of the model due to sample self-selection bias, we adopted the propensity score matching and difference-in-differences (PSM-DID) model to examine the effect of VCs on innovation. We also set the antecedent and lagged terms of the policy variables to examine the parallel trend of the model and the lag of the VC effect to improve the reliability of the research findings.

\section{Theory and Hypotheses}

2.1. The Effect of VCs on Firm Innovation. Venture capital in this paper is a kind of financing method that mainly provides financial support to start-up firms with growth potential and obtains shares of firms. VCs operate mainly by investing in equity stakes of start-up firms with growth potential and exiting generally by initiating an initial public offering (IPO), merger/acquisition, or other equity transfer to earn excess investment returns [12]. The profit-seeking nature of capital means that VCs inherently have no direct incentive to stimulate firm innovation. If VCs want to share the benefits of long-term firm growth and do not have a strong demand to cash in short-term investment returns, they may be inclined to endorse or even assist firms in their innovation activities to build a foundation that supports a sustained increase in the firms' valuation levels [39]. However, if VCs are more focused on short-term interests or are influenced by the "grandstanding" motive, that is, exiting quickly after helping firms succeed in an IPO and providing investors with high returns to build their reputations in the industry [40], then they may be more inclined to require firms to go public as soon as possible to realize a return on their investment. In this case, firms may be forced to adjust their original development plans, keep increasing their market size, focus more on financial performance, commercialize their existing technologies [34], and reduce their innovation inputs, which in turn may prevent them from raising their 
innovation levels. This is because although the level of innovation is an important indicator to assess and enhance the value of a firm [36], improving a firm's innovation level is riskier and more costly and takes longer than enhancing its financial performance [30]. In recent years, some scholars put forward the view that VCs obviously have two sides. In addition to enhancing business performance through valueadded services, there is also "expropriation" of start-up firms; that is, VCs may take a dominant position in a firm by diluting the entrepreneur's equity and then seize or sell the innovation outcomes of the portfolio firm to obtain investment returns, or sequester the new innovative technology of the portfolio firm to ensure that the original technology of their affiliated firms maintains a market monopoly [35, 41]. Under these circumstances, the entry of a $\mathrm{VC}$ is not conducive to the development of innovation activities and prevents portfolio firms from improving their innovation levels.

In the Chinese capital market, at least two important factors may generally enable VCs to show different decisionmaking behaviors from those in mature capital markets, resulting in a negative impact on the innovation level of their portfolio firms. On the one hand, VCs are overall relatively young in the emerging Chinese capital market. Although the total amount of capital is large, there are a large number of institutions, mostly small- and medium-sized VCs [42]. Compared to the few foreign VCs in the market, they are relatively inexperienced, possess weak risk tolerance and control capabilities, and generally have a clear "grandstanding" motive [41, 42]. These characteristics make it obvious that Chinese VCs are motivated by short-term investment goals. This phenomenon is also corroborated by relevant data. In a study of Chinese firms listed on the SME and GEM boards from 2004 to 2013, [41] finds that nearly half of the VC-backed firms received their capital injections two years before IPO, among which nearly $50 \%$ received their capital injections one year before IPO or in the year of IPO. Clearly VCs in the Chinese capital market may exhibit stronger short-term investment goals than in mature capital markets [40-42]. This pursuit of short-term interest contradicts the long-term nature of firms' innovation activities, which is not conducive to the development of their innovation activities and raising their innovation levels.

On the other hand, VCs' decisions are influenced largely by the institutional environment [42]. In mature economies, such as North America and Western Europe, the legal environment is more developed and transparent, so VCs can to mitigate unsystematic risks more easily [43]. However, in emerging capital markets such as China, the market system and legal system are not yet well developed, and intellectual property protection is still continuously improving [42-45]. In such an environment, VCs may face increasing unsystematic risks, be forced to shorten the investment time to minimize the risks, and thereby form a tendency to decide to cash short-term investment returns. Such an environment may also result in insufficient protection of the innovation achievements of portfolio firms, leaving room for "expropriation" by VCs. This leads to the theft of the innovation outcomes of firms, which is not conducive to improving the portfolio firms' innovation levels.

Based on these two factors, we propose the following hypothesis.

Hypothesis 1. In the Chinese capital market, the entry of a $\mathrm{VC}$ is not conducive to the improvement of the portfolio firms' innovation levels.

2.2. Moderating Effects of Firm Heterogeneity. In the Chinese capital market, VC in general may have inhibited the innovation level of portfolio firms. However, the observations of some cases reveal that some firms indeed improved their innovation levels significantly after receiving capital injections from VCs [41]. Some studies also explained this phenomenon in terms of the heterogeneity of VCs. However, VC activities are not only the unilateral outputs of VCs to portfolio firms, but embody the bilateral or even multilateral interaction between VCs and firms [33]. Therefore, if we consider only the heterogeneity of VCs, then we ignore the subjective position of firms in their innovation activities to some extent. Some firms have special needs for technological innovation, and such needs may better explain the heterogeneous effects of VCs on innovation. With this consideration, we further revealed the different impacts of VC on firm innovation from the perspective of firms, specifically from the characteristics of technology preferences, that is, in terms of firm type and the firm's actual controller.

First, firms are technology dependent. Compared to other firms, the growth and performance of some firms depend largely on the results of technological innovation, or the level of technological innovation plays an important role in the growth and future valuation of some firms. We refer to such firms as technology-dependent firms in this paper. Unlike other types of firms that can increase their value and financial performance by expanding their market size, improving their marketing strategies, and enhancing the commercialization of existing technologies, these firms need to continuously innovate through technology to maintain their competitiveness and form technological barriers to increase their value. The level of innovation is the core indicator to measure the value of a firm, and it is the basis and important means to improve the development and performance of a firm. It can be said that improving the innovation level of technology-dependent firms has a positive effect on both their own development and the return goal of the VC. Therefore, considering investment goals, VCs are more likely to be willing to use their resources and intelligence to help improve the innovation level of technology-dependent firms than other types of firms. Firms will also try to mitigate the negative impact on its ability to improve its level of innovation and maintain its core competitiveness in terms of technology level.

Second, we examine the case when the actual controller of a firm is an expert in the same industry. When an industry expert is the actual controller of a firm, he or she is more able 
to fully recognize the importance of technological innovation for the future development of the firm [45]. This type of controller will be an active decision maker in promoting a higher level of innovation when the overall financing constraints of the firm are relaxed [46]. In addition, the actual controller of a firm, as an expert in the same industry, is more likely to use his or her control over the firm and can fully understand the technology to make VCs aware of the huge potential of innovation activities in improving the future valuation of the firm and the importance of his or her role and that of the team in the process. This can mitigate the strong short-term investment impulse of VC entry and the possible expropriation by VCs, thus effectively counteracting the negative impact of VCs on the innovation level of firms.

Based on the above analysis, we propose the following hypotheses.

Hypothesis 2. Compared to other firms, technology-dependent firms with VC backing can counteract the adverse effects of VCs on the improvement of the firm's innovation level.

Hypothesis 3. Compared to other firms, firms with their actual controllers being technical experts in the same industry are able to counteract the adverse effects of VCs on the firm innovation level after accepting VC.

\section{Methodology}

3.1. Sample and Data. According to [29, 35], we selected Chinese GEM-listed firms (excluding financial firms) from 2008 to 2017 as the initial sample. GEM-listed firms were chosen because promising innovative Chinese firms usually choose GEM for listing. The study period started from 2008 because the R\&D data of some firms in 2007 and before were unavailable. Since there is a lag of two or three years in the publication of patent applications in China, the end year of the study period was set to 2017 to alleviate the truncation problem caused by the unpublished patent applications. The data sources are as follows: (i) whether firms had VC backing and the timing of their first round of financing were determined jointly using firms' financing history data in the CVSource investment database and firms' prospectuses; (ii) patent data were obtained from the website of the State Intellectual Property Office of China using the names of the sample firms as the index; (iii) R\&D data were obtained from firms' prospectuses and the China Stock Market and Accounting Research (CSMAR) database; and (iv) other data used for empirical analysis were collected mainly from the Wind and CSMAR databases.

\subsection{Variables}

3.2.1. Dependent and Independent Variables. The explained variable is the level of firm innovation, which can be measured in three ways. First, the impact of VC on firm innovation inputs is examined using the logarithm of $R \& D$ investment (LnRD). Second, the impact of VCs on the quantity of innovation outputs is examined using the logarithm of the total number of patent applications filed by the firms (LnPatent). Third, the logarithm of the total number of invention patent applications filed by the firms (LnInvention) is used to measure the impact of VCs on the quality of innovation outputs. Some firms have not applied for patents in the sample period, and thus the value of Patent and Invention are 0 . To avoid missing values when taking the logarithm directly, we changed the number of patent applications and invention patent applications of such samples to the value of 1 and then took the logarithms. The explanatory variable is the dummy variable Treatvc, which equals 1 when a firm has investment from at least one $\mathrm{VC}$ during the year and 0 otherwise.

3.2.2. Control Variables. Control variables are set with reference to existing research: (i) firm size (Size) is measured by the firm's total assets at the end of the year to control the impact of the firm's own size characteristics on innovation $[22,47]$; (ii) firm capital structure (Lev) is expressed by the firm's liability-assets ratio to control the impact of different capital structures on innovation activities [16, 22]; (iii) firm age (Age) is measured using the natural logarithm of the number of years and the firm was effectively established during the sample period to control the impact of the firm's development stage on innovation activities [48]; (iv) firm profitability (Roa) is measured using the ratio of the firm's net profit for the year to its total assets at the end of the year to control for the impact of different levels of profitability on innovation activities [49]; (v) firm solvency (PPEperc) is measured using the ratio of current year-end fixed assets to year-end total assets to control the impact of solvency on innovation activities [50].

After removing the sample firms with missing data, we obtained an initial sample of 363 firms, with a total sample size of 3,630 observations. Among them, 233 firms had VC backing, accounting for $64.18 \%$. This indicates that more than half of the GEM-listed firms had VC backing before IPO during the sample period. Figure 1 shows the distribution of the timing of VC entry in the firms. Distribution type 1 indicates the proportion of VCs entering firms in different years before IPO. Among them, the solid line indicates the proportion of firms with VCs shareholding before the year of IPO, and the dotted line indicates the cumulative value of the above data (similar with Distribution type 2). For example, " 5 " of $X$-axis in the Distribution type 1 means that less than $20 \%$ of firms received venture capital 2 years before the IPO. The data show that among VC-backed firms, more than $50 \%$ had VC entry only 2 years before the IPO and only $13.18 \%$ of firms had VC entry 5 years or more before IPO, which indicates that VCs clearly have a shortterm investment nature. Distribution type 2 indicates the proportion of time of VC entry in the period from the firm's establishment to its IPO. For example, " 50 " of $X$-axis in the Distribution type 2 means the first $50 \%$ of the time period from the establishment to IPO. The data show that only $21.32 \%$ of the firms had VC backing in the first $50 \%$ of the time period from the establishment to IPO, while more than $50 \%$ of the firms had VC entry in the remaining $30 \%$ of the 


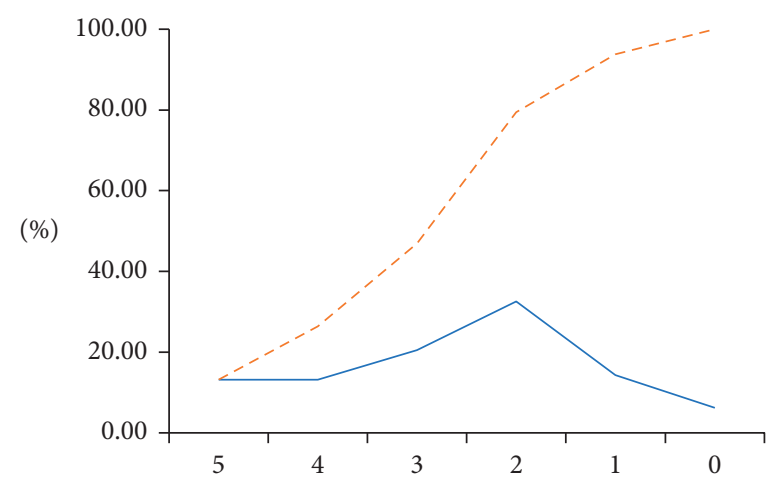

(a)



(b)

FIgure 1: Distribution of the timing of VC entry in firms. (a) Distribution type 1. (b) Distribution type 2.

time period prior to IPO, which is basically consistent with the situation shown in Distribution type 1 .

3.3. Model. Endogeneity is a common challenge for research on the impact of VCs on firms $[32,51]$. For the research question in this paper, it is possibly not the involvement of VC that increases the innovation level of firms, but rather that the VC selects more innovative firms before investment [52]. To mitigate the possible endogeneity of the model due to the self-selection of the sample mentioned above, we constructed a time-varying DID model to test the impact of VCs on firm innovation. We also used the PSM method to ensure that the sample firms with VC backing (treatment group) will match the most proximate non-VC-backed firms (control group). The model is finally set up as follows:

$$
\begin{aligned}
y_{i t}= & \alpha+\sum_{\tau=1}^{2} \theta_{-\tau} \operatorname{Treatvc}_{i, t-\tau}+\theta \operatorname{Treatvc}_{i t}+\sum_{\tau=1}^{4} \theta_{+\tau} \operatorname{Treatvc}_{i, i+\tau} \\
& +\beta^{\prime} X_{i t}+\lambda_{t}+\mu_{i}+\varepsilon_{i t},
\end{aligned}
$$

where $y_{i t}$ is the explained variable, $X_{i t}$ is a set of virtual variables, and Treatvc $c_{i t}$ is a policy variable. The coefficients $\theta_{\tau}$ and $\theta_{\tau}(\tau=1, \ldots, 4)$ are the policy effects we will examine, where the former indicates the policy effect in the year of VC entry and the latter mainly accounts fort the innovation effect of VCs on a certain lag. For this reason, we added $\sum_{\tau=1}^{4} \theta_{+\tau}$ Treatvc $_{i, i+\tau}$ to examine the long-term significance and dynamic trend of the policy effect. $\alpha$ is a constant term, $\mu_{i}$ is the individual fixed effect, $\lambda_{t}$ is the time fixed effect, and $\varepsilon_{i t}$ is the residual term. $\sum_{\tau=1}^{2} \theta_{-\tau}$ Treatvc $_{i, t-\tau}$ is added to test the parallel trend hypothesis of the DID model.

When matching the sample firms in the control group, we let the three explained variables and five control variables in model (1) be the matching variables, matched individually using the nearest neighbor matching (NNM) method. The results are shown in Table 1 . Before matching, we found significant differences between the treatment and control groups in indicators such as firm size, firm age, solvency, capital structure, profitability, and R\&D investment. The deviations between the two sample groups were no longer statistically significant after matching. The differences in the number of patent and invention patent applications also decreased to different degrees after matching. In general, the sample matching effect was effective.

\section{Results}

4.1. Regression Analysis: Impact of VCs on Firm Innovation. The regression results for the impact of VCs on firm innovation are presented in Table 2, where Models 1-3 are fullsample regressions and Models 4-6 are PSM sample regressions. In terms of innovation inputs, the results of the full-sample regression (Model 1) show that compared to non-VC-backed firms, VCs had no significant impact on the $\mathrm{R} \& \mathrm{D}$ investment of their portfolio firms in the year they entered, but a significant inhibitory effect in the second year. This treatment effect continued and showed a gradual weakening trend in the following two years until the impact of VCs on firms' R\&D investment was no longer significant in the fifth year. In terms of the cumulative treatment effect, the cumulative impact coefficient for the entire five-year time window was -1.323 and significant at the $1 \%$ level according to the Wald joint test, indicating that the VC's entry had a significant inhibitory effect on the R\&D investment of its portfolio firms in the five-year period. This conclusion was also roughly supported by the PSM sample regression results (Model 4). However, the PSM regression results were weaker than the results of the full-sample regression, suggesting that the endogeneity of the model amplified the adverse effect of VCs on the R\&D investment of portfolio firms. In addition, the entry of a VC also adversely affects the quantity and quality of innovation outputs of its portfolio firms in a similar way to innovation inputs. Particularly in the case of patent applications, which measure the quality of innovation outputs, VC entry significantly inhibited the number of patent applications in the year of $\mathrm{VC}$ entry, and this effect tended to increase and then decrease in the following four years.

According to the above analysis, the entry of VC inhibited the innovation level of the portfolio firms in the sample. In particular, it had a negative impact on both innovation inputs and outputs. This result was particularly 
TABLE 1: Change in deviations for the treatment and control groups after matching.

\begin{tabular}{|c|c|c|c|c|c|c|c|}
\hline \multirow{2}{*}{ Variable symbol } & \multirow{2}{*}{$\begin{array}{l}\text { U (before matching) } \\
\text { M (after matching) }\end{array}$} & \multicolumn{2}{|c|}{ Average value } & \multicolumn{2}{|c|}{ Change in deviation (\%) } & \multicolumn{2}{|c|}{$T$-test } \\
\hline & & Treatment group & Control group & Deviation rate & Reduction rate & $T$-value & $P$ value \\
\hline \multirow[b]{2}{*}{ Size } & $\mathrm{U}$ & 0.197 & 0.120 & 34.8 & \multirow[b]{2}{*}{94.8} & 9.73 & $\leq 0.001$ \\
\hline & $\mathrm{M}$ & 0.185 & 0.189 & -1.8 & & -0.61 & 0.540 \\
\hline \multirow{2}{*}{ Lev } & $\mathrm{U}$ & 0.290 & 0.324 & -19.1 & \multirow{2}{*}{75.3} & -5.70 & $\leq 0.001$ \\
\hline & M & 0.288 & 0.280 & 4.7 & & 1.63 & 0.104 \\
\hline \multirow{2}{*}{ Age } & $\mathrm{U}$ & 2.475 & 2.345 & 25.9 & \multirow{2}{*}{99.6} & 7.76 & $\leq 0.001$ \\
\hline & M & 2.474 & 2.475 & -0.1 & & -0.04 & 0.971 \\
\hline \multirow{2}{*}{ Roa } & $\mathrm{U}$ & 0.090 & 0.115 & -26.2 & \multirow{2}{*}{93.7} & -7.86 & $\leq 0.001$ \\
\hline & M & 0.090 & 0.087 & 1.7 & & 0.62 & 0.535 \\
\hline \multirow{2}{*}{ PPEperc } & $\mathrm{U}$ & 0.159 & 0.181 & -18.0 & \multirow{2}{*}{74.8} & -5.36 & $\leq 0.001$ \\
\hline & M & 0.159 & 0.165 & -4.5 & & -1.57 & 0.116 \\
\hline \multirow{2}{*}{ LnPatent } & $\mathrm{U}$ & 2.289 & 1.904 & 25.4 & \multirow{2}{*}{68.8} & 7.47 & $\leq 0.001$ \\
\hline & M & 2.272 & 2.392 & -7.9 & & -2.57 & 0.010 \\
\hline \multirow{2}{*}{ LnInvention } & $\mathrm{U}$ & 1.543 & 1.193 & 26.6 & \multirow{2}{*}{59.1} & 7.75 & $\leq 0.001$ \\
\hline & M & 1.526 & 1.669 & -10.9 & & -3.43 & 0.001 \\
\hline \multirow{2}{*}{ LnRD } & $\mathrm{U}$ & 17.123 & 16.737 & 38.2 & \multirow{2}{*}{91.6} & 11.19 & $\leq 0.001$ \\
\hline & M & 17.111 & 17.143 & -3.2 & & -1.05 & 0.292 \\
\hline
\end{tabular}

Note. The "deviation rate" is calculated using $\left(x_{t}-x_{u}\right) / \sigma_{t}$, where $x_{t}$ and $x_{u}$ are the mean values of the variables in the treatment and control groups, respectively, and $\sigma_{t}$ is the standard error of the corresponding variables in the treatment group. The "reduction rate" is the percentage change between the absolute value of the initial deviation and the absolute value of the deviation after matching.

evident in the second year of VC entry. Although the effect gradually decreased in degree, the overall cumulative effect was significantly negative. Therefore, Hypothesis 1 was supported empirically. In addition, the coefficients of Treatvc $_{i, t-\tau}(\tau=1,2)$ for Models $1-6$ were insignificant, indicating that the DID model satisfies the parallel trend hypothesis.

The innovation effect of VCs: firm heterogeneity.

We next empirically tested the effect of VCs on the innovation of technology-dependent firms and firms whose actual controllers are experts in the same industry from the perspective of portfolio firms. First, it is necessary to formulate the method for defining technology-dependent firms based on their connotation in the previous section. As the level of technological innovation of high-tech firms is the core element in measuring their firm value, it is also the basis and important means for firm development and performance improvement [53]. Therefore, based on the Catalogue of Statistical Classification of High-Tech Industries published by the National Bureau of Statistics of China in 2002 and the industry classification of listed firms in the CSMAR database, we initially selected 151 firms from 233 sample firms with VC backing and their matching samples as technology-dependent firms and regarded the remaining as non-technology-dependent firms. A grouped regression using (1) revealed that the regression coefficients of the policy variables for the sample group of technology-dependent firms were all significantly negative, which was inconsistent with Hypothesis 2. A further analysis of the data reveals that some of the technology-dependent sample firms invested heavily in $\mathrm{R} \& \mathrm{D}$. However, the numbers of patent applications and invention patent applications were low and mainly distributed in a few industries such as pharmaceutical manufacturing, indicating that the number of patent applications can hardly measure the innovation output of such firms. For this reason, we removed the 56 firms with an average annual number of patent applications of less than 10 among the technology-dependent firms with VC backing and performed the regression analysis again using the same method. Since the full-sample regression results were similar to the PSM sample regression results, we report only the latter in Table 3.

In terms of innovation inputs, the regression results for technology-dependent firms (Model 1) were similar to that of Model 4 in Table 2. That is, VCs began to significantly inhibit innovation inputs from the second year of VC entry, and this effect then showed a weakening trend. The difference, however, is that the weakening trend was more rapid and the cumulative effect of the five-year time window was no longer significant, suggesting that the possible negative impact of VCs on the innovation of technologydependent firms was effectively mitigated. These findings were further supported in a comparison with the regression results for non-technology-dependent firms (Model 2). In terms of the number of innovation outputs, the results of Model 3 show that the entry of VCs exhibited a significant and sustained positive effect on the number of patents of technology-dependent firms. We compared the regression results for non-technology-dependent firms (Model 4) and the regression results for the ungrouped sample firms in Model 5 in Table 2. The comparison shows that technologydependent firms not only effectively mitigated the possible negative impact of VC entry on the quantity of their innovation outputs, but also boosted the quantity of new outputs. The regression results for the quality and quantity of innovation outputs were similar, except that the positive effect on the quality of innovation outputs was slightly weaker than that on the quantity of innovation outputs. Based on the above analysis, it is clear that technologydependent firms can effectively mitigate the negative impact of VC entry on their innovation activities compared to other firms, as evidenced by a reduced inhibitory effect on 
TABLE 2: Regression results: impact of VCs on the innovation level of their portfolio firms.

\begin{tabular}{|c|c|c|c|c|c|c|}
\hline \multirow[b]{2}{*}{ Variable name } & \multicolumn{3}{|c|}{ Full-sample regression } & \multicolumn{3}{|c|}{ PSM sample regression } \\
\hline & $\begin{array}{l}\text { Model } 1 \\
\text { LnRD }_{i t}\end{array}$ & $\begin{array}{c}\text { Model } 2 \\
\text { LnPatent }_{i t}\end{array}$ & $\begin{array}{c}\text { Model } 3 \\
\text { LnInvention }_{i t}\end{array}$ & $\begin{array}{l}\text { Model } 4 \\
\text { LnRD }_{i t}\end{array}$ & $\begin{array}{c}\text { Model } 5 \\
\text { LnPatent }_{i t}\end{array}$ & $\begin{array}{c}\text { Model } 6 \\
\text { LnInvention }_{i t}\end{array}$ \\
\hline Treatvc $_{i, t-2}$ & $-0.025(0.101)$ & $-0 . .025(0.215)$ & $-0.304(0.310)$ & $-0.221(0.301)$ & $-0.018(0.314)$ & $-0.294(0.311)$ \\
\hline Treatvc $_{i, t-1}$ & $-0.058(0.097)$ & $-0.001(0.201)$ & $0.049(0.225)$ & $-0.079(0.086)$ & $0.005(0.199)$ & $0.056(0.224)$ \\
\hline Treatvc $_{i t}$ & $0.218(0.260)$ & $-0.019(0.222)$ & $-0.267^{*}(0.206)$ & $0.196(0.224)$ & $-0.023(0.221)$ & $\begin{array}{c}-0.393^{* * *} \\
(0.103)\end{array}$ \\
\hline $\operatorname{Treatvc}_{i, t+1}$ & $\begin{array}{c}-0.684^{* * *} \\
(0.102)\end{array}$ & $\begin{array}{c}-0.360^{* * *} \\
(0.087)\end{array}$ & $-0.559^{* * *}(0.118)$ & $\begin{array}{c}-0.575^{* * *} \\
(0.125)\end{array}$ & $\begin{array}{c}-0.345^{* * *} \\
(0.031)\end{array}$ & $-0.401^{* * *}(0.101)$ \\
\hline Treatvc $_{i, t+2}$ & $-0.231^{*}(0.142)$ & $\begin{array}{c}-0.304^{* * *} \\
(0.057)\end{array}$ & $-0.368^{*}(0.221)$ & $\begin{array}{c}-0.413^{* * *} \\
(0.086)\end{array}$ & $\begin{array}{c}-0.300^{* * *} \\
(0.025)\end{array}$ & $-0.361^{*}(0.220)$ \\
\hline Treatvc $_{i, t+3}$ & $-0.673^{*}(0.416)$ & $0.058(0.117)$ & $0.007(0.132)$ & $0.372^{* * *}(0.037)$ & $0.051(0.117)$ & $-0.003(0.132)$ \\
\hline Treatvc $_{i, t+4}$ & $0.047(0.064)$ & $-0.213^{*}(0.092)$ & $\begin{array}{c}-0.240^{* * *} \\
(0.059)\end{array}$ & $0.043(0.337)$ & $-0.109(0.091)$ & $-0.241^{*}(0.135)$ \\
\hline Cumulative effect & $-1.323^{* * *}$ & $-0.838^{* *}$ & $-1.427^{* *}$ & $-0.377^{* * *}$ & $-0.726^{*}$ & $-1.399^{* * *}$ \\
\hline Firm FE & Yes & Yes & Yes & Yes & Yes & Yes \\
\hline Year FE & Yes & Yes & Yes & Yes & Yes & Yes \\
\hline $\begin{array}{l}\text { Number of } \\
\text { observations }\end{array}$ & 3630 & 3630 & 3630 & 4660 & 4660 & 4660 \\
\hline Adj. $R$-sq & 0.5692 & 0.4128 & 0.3986 & 0.5128 & 0.4956 & 0.3357 \\
\hline
\end{tabular}

Note. The symbols ${ }^{* * *},{ }^{* *}$, and ${ }^{*}$ indicate significance at the $1 \%, 5 \%$, and $10 \%$ levels, respectively. The robust standard errors are reported in parentheses. The regression coefficients for each control variable are not given due to space limitations of this paper.

TABLE 3: PSM sample regression results: impact of VC on the innovation level of technology-dependent firms.

\begin{tabular}{|c|c|c|c|c|c|c|}
\hline \multirow[b]{2}{*}{ Variable name } & \multicolumn{2}{|c|}{$\operatorname{LnRD}_{i t}$} & \multicolumn{2}{|c|}{ LnPatent $_{i t}$} & \multicolumn{2}{|c|}{ LnInvention $_{i t}$} \\
\hline & $\begin{array}{c}\text { Model } 1 \\
\text { Sample A }\end{array}$ & $\begin{array}{c}\text { Model } 2 \\
\text { Sample B }\end{array}$ & $\begin{array}{c}\text { Model } 3 \\
\text { Sample A }\end{array}$ & $\begin{array}{c}\text { Model } 4 \\
\text { Sample B }\end{array}$ & $\begin{array}{r}\text { Model } 5 \\
\text { Sample A }\end{array}$ & $\begin{array}{c}\text { Model } 6 \\
\text { Sample B }\end{array}$ \\
\hline Treatvc $_{i, t-2}$ & $-0.065(0.131)$ & $0.222(0.312)$ & $0.180(0.408)$ & $-0.609(0.181)$ & $-0.150(0.387)$ & $-0.383(0.416)$ \\
\hline Treatvc $_{i, t-1}$ & $-0.219(0.200)$ & $0.042(0.051)$ & $-0.035(0.225)$ & $0.132(0.164)$ & $-0.152(0.284)$ & $0.208(0.389)$ \\
\hline Treatvc $c_{i t}$ & $0.215(0.278)$ & $-0.251^{* * *}(0.041)$ & $-0.116(0.250)$ & $0.156(0.161)$ & $-0.428^{*}(0.122)$ & $-0.502^{* * *}(0.124)$ \\
\hline $\operatorname{Treatvc}_{i, t+1}$ & $-0.336^{* * *}(0.084)$ & $-0.412^{* * *}(0.062)$ & $0.251^{* *}(0.120)$ & $-0.389^{* * *}(0.116)$ & $0.185^{* * *}(0.013)$ & $-0.296^{* * *}(0.076)$ \\
\hline Treatvc $_{i, t+2}$ & $-0.127(0.131)$ & $-0.345^{* * *}(0.110)$ & $0.485^{* *}(0.229)$ & $-0.232^{* * *}(0.056)$ & $0.172 *(0.096)$ & $-0.365^{* * *}(0.113)$ \\
\hline $\operatorname{Treatvc}_{i, t+3}$ & $-0.046^{*}(0.026)$ & $-0.119^{* *}(0.056)$ & $0.147(0.158)$ & $-0.175^{*}(0.097)$ & $0.201(0.253)$ & $-0.101^{*}(0.059)$ \\
\hline Treatvc $_{i, t+4}$ & $-0.006(0.021)$ & $0.035(0.051)$ & $0.144^{*}(0.080)$ & $-0.114(0.128)$ & $0.217^{*}(0.128)$ & $-0.126(0.122)$ \\
\hline Cumulative effect & -0.300 & $-1.902^{* * *}$ & $0.911^{* *}$ & $-0.745^{* * *}$ & $0.347^{*}$ & $-1.390^{* * *}$ \\
\hline Firm FE & Yes & Yes & Yes & Yes & Yes & Yes \\
\hline Year FE & Yes & Yes & Yes & Yes & Yes & Yes \\
\hline Number of observations & 1900 & 2760 & 1900 & 2760 & 1900 & 2760 \\
\hline Adj. $R$-sq & 0.6894 & 0.5986 & 0.4986 & 0.5984 & 0.4589 & 0.6983 \\
\hline
\end{tabular}

Note. The symbols ${ }^{* * *},{ }^{* *}$, and ${ }^{*}$ indicate significance at the $1 \%, 5 \%$, and $10 \%$ levels, respectively. The robust standard errors are reported in parentheses. The regression coefficients for each control variable are not given due to space limitations of this paper.

innovation inputs and a significant positive effect on both the quantity and quality of innovation outputs. Therefore, Hypothesis 2 partially held.

Can a firm whose actual controller is an expert in the same industry mitigate the adverse effects of VC on the firm's level of innovation mitigated after receiving the investment? An empirical test was performed on this question. Regarding the definition of a firm's actual controller as an expert in the same industry, we mainly referred to the description of the actual controller in the firm's prospectus. When the actual controller of a firm is an individual with a bachelor's degree or above and his or her major is similar to the industry to which the firm belongs, he or she is considered as an expert in the same industry. Based on the above criteria, we obtained $79 \mathrm{VC}$-backed firms of this type (firms with an average annual number of patent applications below 10 were removed). By adding matching samples, we obtained 158 firms to constitute Sample C, with the remaining 308 firms constituting Sample D. Regressions were conducted in groups using (1). The PSM sample regression results are presented in Table 4.

Model 1 shows that the cumulative effect of VC entry on innovation inputs does not have a significant negative effect when the actual controller is an industry expert, and VC also has a short-term positive effect in the second year of entry. The corresponding Model 2 shows that the entry of a VC has a significant negative effect on the innovation inputs of portfolio firms when the actual controller is not an expert in the same industry, which is consistent with the results for Models 1 and 4 in Table 2. Models 3 and 5 show similar 
TABLE 4: Regression results: impact of VCs on the innovation level of firms whose actual controllers are experts in the same industry.

\begin{tabular}{|c|c|c|c|c|c|c|}
\hline \multirow[b]{2}{*}{ Variable name } & \multicolumn{2}{|c|}{$\mathrm{RD}_{i t}$} & \multicolumn{2}{|c|}{ LnPatent $_{i t}$} & \multicolumn{2}{|c|}{ LnInvention $_{i t}$} \\
\hline & $\begin{array}{c}\text { Model } 1 \\
\text { Sample C }\end{array}$ & $\begin{array}{c}\text { Model } 2 \\
\text { Sample D }\end{array}$ & $\begin{array}{c}\text { Model } 3 \\
\text { Sample C }\end{array}$ & $\begin{array}{c}\text { Model } 4 \\
\text { Sample D }\end{array}$ & $\begin{array}{l}\text { Model } 5 \\
\text { Sample C }\end{array}$ & $\begin{array}{c}\text { Model } 6 \\
\text { Sample D }\end{array}$ \\
\hline Treatvc $_{i, t-2}$ & $-0.051(0.225)$ & $0.210(0.358)$ & $-0.091(0.288)$ & $0.061(0.308)$ & $0.688(0.522)$ & $-1.012(0.261)$ \\
\hline $\operatorname{Treatvc}_{i, t-1}$ & $-0.176(0.386)$ & $0.037(0.056)$ & $0.008(0.147)$ & $-0.207(0.396)$ & $-0.149(0.275)$ & $0.166(0.225)$ \\
\hline Treatvc $_{i t}$ & $-0.226(0.557)$ & $-0.246^{* * *}(0.027)$ & $-0.154^{*}(0.086)$ & $0.143(0.425)$ & $-0.598(0.463)$ & $-0.346^{* * *}(0.018)$ \\
\hline Treatvc $_{i, t+1}$ & $0.237^{*}(0.132)$ & $-0.469^{* * *}(0.065)$ & $0.148(0.220)$ & $-0.342^{* * *}(0.092)$ & $0.185(0.219)$ & $-0.097^{* * *}(0.116)$ \\
\hline Treatvc $_{i, t+2}$ & $0.006(0.101)$ & $-0.340^{* *}(0.148)$ & $0.268(0.246)$ & $-0.309^{* * *}(0.025)$ & $0.471^{* *}(0.220)$ & $-0.022(0.041)$ \\
\hline Treatvc $_{i, t+3}$ & $0.023(0.048)$ & $-0.066(0.061)$ & $0.185^{* *}(0.089)$ & $-0.051(0.149)$ & $0.218(0.271)$ & $-0.222^{* * *}(0.015)$ \\
\hline Treatvc $_{i, t+4}$ & $-0.076(0.100)$ & $0.058(0.060)$ & $0.102(0.219)$ & $-0.151^{*}(0.081)$ & $0.202^{*}(0.123)$ & $-0.275(0.226)$ \\
\hline Cumulative effect & -0.036 & $-1.063^{* * *}$ & 0.549 & $-0.71^{* * *}$ & 0.478 & $-0.962^{* *}, *$ \\
\hline Firm FE & Yes & Yes & Yes & Yes & Yes & Yes \\
\hline Year FE & Yes & YES & YES & YES & YES & YES \\
\hline Number of observations & 1580 & 3080 & 1580 & 3080 & 1580 & 3080 \\
\hline Adj. $R$-sq & 0.3968 & 0.4756 & 0.5214 & 0.6898 & 0.4269 & 0.7856 \\
\hline
\end{tabular}

Note. The symbols ${ }^{* * *},{ }^{* *}$, and ${ }^{*}$ indicate significance at the $1 \%, 5 \%$, and $10 \%$ levels, respectively. The robust standard errors are reported in parentheses. The regression coefficients for each control variable are not given due to space limitations of this paper.

findings to Model 1 . That is, compared to other types of firms, firms whose actual controllers are experts in the same industry are able to effectively mitigate the impact of VC entry on the quantity and quality of the firms' innovation outputs, and VCs even show a certain positive impact in the third or fourth year. In summary, the negative impact of VC on firms' innovation inputs is effectively mitigated when it invests in firms whose actual controllers are experts in the same industry compared to other firms, and to some extent, VC promotes the improvement of firms' innovation outputs. Therefore, Hypothesis 3 holds.

\section{Conclusion}

The great contribution of innovation to firm development and economic growth, as well as the positive role of VCs in the growth of start-up firms, indicates the importance of studying the impact of $\mathrm{VsC}$ on firm innovation in both theory and practice. Using Chinese GEM-listed firms for 2008-2017 as the research sample, this study empirically examines the impact of VCs on firm innovation using a PSM-DID model. The results indicate that, overall, the entry of a VC inhibits the innovation inputs and outputs of portfolio firms due to factors such as the grandstanding motive and the expropriation effect. In particular, there is a decrease in $\mathrm{R} \& \mathrm{D}$ investment and in the number of patent and invention patent applications. The inhibitory effect gradually diminishes over time, indicating that the incentive policies directly targeting VCs do help to improve firms' innovation in practice. However, two types of firms with "technology preference," namely technology-dependent firms and firms in which the actual controller is an expert in the same industry, can effectively mitigate the negative impact of VC entry on their innovation activities and can take advantage of their resources and experience to boost their innovation outputs.

This paper has three policy implications. First, the current VC support policies should be further optimized, universal policies such as tax concessions should be shifted to target investment projects, and great support should be laid on VC financing projects with higher technological attributes and higher financing pressure. Second, policymakers should pay more attention to VC financing projects when entering start-up firms. The government can also guide and encourage VCs in the investment stage by setting up a compensation fund for early-stage investment risks. Finally, policies should further encourage VCs to perform their certification function and provide value-added services to comprehensively enhance the overall strength and innovation level of firms and guide VC institutions in aligning their investment goals with the long-term development of such firms to ensure the sustainability of firm innovation as far as possible.

\section{Data Availability}

Data are available on request to the first author Han Qiao (e-mail: 10080150@vip.henu.edu.cn).

\section{Conflicts of Interest}

The authors declare that they have no conflicts of interest.

\section{Acknowledgments}

This research was funded by the Project of National Social Science Foundation of China with grant number (20CTJ013).

\section{References}

[1] K. J. Arrow, "Economic welfare and the allocation of resources for invention," in The Rate and Direction of Inventive Activity: Economic and Social Factors, R. R. Nelson, Ed., Princeton University Press, Princeton, NJ, USA, pp. 609-626, 1962.

[2] B. Aschhoff, "The effect of subsidies on R\&D investment and success: do subsidy history and size matter?" ZEW-Centre for European Economic Research Discussion, vol. 32, 2019.

[3] E. Özçelik and E. Taymaz, "R\&D support programs in developing countries: the Turkish experience," Research Policy, vol. 37, no. 2, pp. 258-275, 2008. 
[4] Eurostat, "Research and developmengt expenditure, by sectors of performace," March 2009, https://epp.eurostat.ec. europa.eu.

[5] R. L. Florida and M. Kenney, "Venture capital-financed innovation and technological change in the USA," Research Policy, vol. 17, no. 3, pp. 119-137, 1988.

[6] D. Cumming and S. Johan, "The problems with and promise of entrepreneurial finance," Strategic Entrepreneurship Journal, vol. 11, no. 3, pp. 357-370, 2017.

[7] S. Kortum and J. Lerner, "Assessing the contribution of venture capital to innovation," The RAND Journal of Economics, vol. 31, no. 3, pp. 674-692, 2000.

[8] M. Hirukawa and M. Ueda, "Venture capital and innovation: which is first?" Pacific Economic Review, vol. 16, no. 4, pp. 421-465, 2011.

[9] T. J. Chemmanur, K. Krishnan, and D. K. Nandy, "How does venture capital financing improve efficiency in private firms? A look beneath the surface," Review of Financial Studies, vol. 24, no. 12, pp. 4037-4090, 2011.

[10] F. Bertoni, M. G. Colombo, and A. Quas, "The role of governmental venture capital in the venture capital ecosystem: an organizational ecology perspective," Entrepreneurship Theory and Practice, vol. 43, no. 3, pp. 611-628, 2019.

[11] T. Hellmann and M. Puri, "Venture capital and the professionalization of start-up firms: empirical evidence," The Journal of Finance, vol. 57, no. 1, pp. 169-197, 2002.

[12] D. H. Hsu, "What Do Entrepreneurs pay for venture capital affiliation?" The Journal of Finance, vol. 59, no. 4, pp. 1805-1844, 2004.

[13] J. A. C. Baum and B. S. Silverman, "Picking winners or building them? Alliance, intellectual, and human capital as selection criteria in venture financing and performance of biotechnology startups," Journal of Business Venturing, vol. 19 , no. 3, p. $355,2015$.

[14] M. Wright and A. Lockett, "The structure and management of alliances: syndication in the venture capital industry," Journal of Management Studies, vol. 40, no. 8, pp. 2073-2102, 2003.

[15] G. D. Bruton and D. Ahlstrom, "An institutional view of China's venture capital industry," Journal of Business Venturing, vol. 18, no. 2, pp. 233-259, 2003.

[16] J. Jeong, J. Kim, H. Son, and D.-i. Nam, "The role of venture capital investment in startups' sustainable growth and performance: focusing on absorptive capacity and venture capitalists' reputation," Sustainability, vol. 12, no. 8, pp. 3447-3450, 2020.

[17] Y. V. Hochberg, A. Ljungqvist, and Y. Lu, "Whom you know matters: venture capital networks and investment performance," The Journal of Finance, vol. 62, no. 1, pp. 251-301, 2007.

[18] H. Lahr and A. Mina, "Venture capital investments and the technological performance of portfolio firms," Research Policy, vol. 45, no. 1, pp. 303-318, 2016.

[19] J. Wang and J. Ma, "Measurement of national innovation driving force and its promotion of high-quality development of service industry," International Journal of Sustainable Development and Planning, vol. 15, no. 7, pp. 1059-1065, 2020.

[20] S. Bernstein, X. Giroud, and R. R. Townsend, "The impact of venture capital monitoring," The Journal of Finance, vol. 71, no. 4, pp. 1591-1622, 2016.

[21] E. Pahnke, R. McDonald, D. Wang, and B. Hallen, "Exposed: venture capital, competitor ties, and entrepreneurial innovation," Academy of Management Journal, vol. 58, no. 5, pp. 1344-1360, 2014.
[22] T. J. Chemmanur and P. Fulghieri, "Entrepreneurial finance and innovation: an introduction and agenda for future research," Review of Financial Studies, vol. 27, no. 1, pp. 1-19, 2014.

[23] M. G. Colombo, D. J. Cumming, and S. Vismara, "Governmental venture capital for innovative young firms," The Journal of Technology Transfer, vol. 41, no. 1, pp. 10-24, 2016.

[24] M. Rin and M. Penas, "Venture capital and innovation strategies," Industrial and Corporate Change, vol. 26, no. 5, pp. 781-800, 2017.

[25] J. N. Barrot, "Investor horizon and the life cycle of innovative firms: evidence from venture capital," Management Science, vol. 63, no. 9, pp. 3021-3043, 2016.

[26] M. Islam, A. Fremeth, and A. Marcus, "Signaling by early stage startups: US government research grants and venture capital funding," Journal of Business Venturing, vol. 33, no. 1, pp. 35-51, 2018.

[27] M. G. Colombo, D. D’Adda, and L. H. Pirelli, "The participation of new technology-based firms in EU-funded R\&D partnerships: the role of venture capital," Research Policy, vol. 45, no. 2, pp. 361-375, 2016.

[28] L. Grilli and S. Murtinu, "New technology-based firms in Europe: market penetration, public venture capital, and timing of investment," Industrial and Corporate Change, vol. 24, no. 5, pp. 1109-1148, 2015.

[29] D. Guo and K. Jiang, "Venture capital investment and the performance of entrepreneurial firms: evidence from China," Journal of Corporate Finance, vol. 22, pp. 375-395, 2013.

[30] R. Kelly and H. Kim, "Venture capital as a catalyst for commercialization and high growth," The Journal of Technology Transfer, vol. 43, no. 6, pp. 1466-1492, 2018.

[31] S. Arvanitis and T. Stucki, "The impact of venture capital on the persistence of innovation activities of start-ups," Small Business Economics, vol. 42, no. 4, pp. 849-870, 2014.

[32] D. Engel and M. Keilbach, "Firm-level implications of early stage venture capital investment - an empirical investigation," Journal of Empirical Finance, vol. 14, no. 2, pp. 150-167, 2007.

[33] S. Caselli, S. Gatti, and F. Perrini, "Are venture capitalists a catalyst for innovation?” European Financial Management, vol. 15, no. 1, pp. 92-111, 2009.

[34] M. Ueda, "Banks versus venture capital: project evaluation, screening, and expropriation," The Journal of Finance, vol. 59, no. 1, pp. 601-621, 2004.

[35] H. Ni, T. Luan, Y. Cao, and D. C. Finlay, "Can venture capital trigger innovation? New evidence from China," International Journal of Technology Management, vol. 65, no. 1-4, pp. 189-214, 2014.

[36] A. P. Faria and N. Barbosa, "Does venture capital really foster innovation?" Economics Letters, vol. 122, no. 2, pp. 129-131, 2014.

[37] M. Heil, "Finance and productivity: a literature review," Journal of Economic Surveys, vol. 32, no. 5, pp. 1355-1383, 2018.

[38] D. H. Hsu and R. H. Ziedonis, "Resources as dual sources of advantage: implications for valuing entrepreneurial-firm patents," Strategic Management Journal, vol. 34, no. 7, pp. 761-781, 2013.

[39] P. A. Gompers, "Grandstanding in the venture capital industry," Journal of Financial Economics, vol. 42, no. 1, pp. 133-156, 1996.

[40] J. Wen and G. Feng, "Venture capital and enterprise innovation: tradeoff between expropriation and value-added," Economic Research Journal, vol. 2, pp. 185-199, 2013. 
[41] D. Ahlstrom, G. D. Bruton, and K. S. Yeh, "Venture capital in China: past, present, and future," Asia Pacific Journal of Management, vol. 24, no. 3, pp. 247-268, 2007.

[42] G. Bruton, D. Ahlstrom, and K. S. Yeh, "Understanding venture capital in East Asia: the impact of institutions on the industry today and tomorrow," Journal of World Business, vol. 39 , no. 1 , pp. $72-88,2004$

[43] M. R. Marvel and G. T. Lumpkin, "Technology entrepreneurs' human capital and its effects on innovation radicalness," Entrepreneurship Theory and Practice, vol. 31, no. 6, pp. 807-828, 2007.

[44] N. T. B. Le, S. Venkatesh, and T. V. Nguyen, "Getting bank financing: a study of Vietnamese private firms," Asia Pacific Journal of Management, vol. 23, no. 2, pp. 209-227, 2006.

[45] Q. Gao, C. Wu, L. Wang, and X. Zhao, "The entrepreneur's psychological capital, creative innovation behavior, and enterprise performance," Frontiers in Psychology, vol. 11, pp. 1651-1663, 2020.

[46] A. Muravyev, O. Talavera, and D. Schäfer, "Entrepreneurs' gender and financial constraints: evidence from international data," Journal of Comparative Economics, vol. 37, no. 2, pp. 270-286, 2009.

[47] D. C. Mowery, J. E. Oxley, and B. S. Silverman, "Strategic alliances and interfirm knowledge transfer," Strategic Management Journal, vol. 17, no. S2, pp. 77-91, 1996.

[48] A. Wadhwa, C. Phelps, and S. Kotha, "Corporate venture capital portfolios and firm innovation," Journal of Business Venturing, vol. 31, no. 1, pp. 95-112, 2016.

[49] R. Nahata, "Venture capital reputation and investment performances," Journal of Financial Economics, vol. 90, no. 2, pp. 127-151, 2008.

[50] E. Ughetto, "Assessing the contribution to innovation of private equity investors: a study on European buyouts," Research Policy, vol. 39, no. 1, pp. 126-140, 2010.

[51] P. Arqué-Castells, "How venture capitalists spur invention in Spain: evidence from patent trajectories," Research Policy, vol. 41, no. 5, pp. 897-912, 2012.

[52] M. Peneder, "Technological regimes and the variety of innovation behaviour: creating integrated taxonomies of firms and sectors," Research Policy, vol. 39, no. 3, pp. 323-334, 2010.

[53] M. Makri and T. A. Scandura, "Exploring the effects of creative CEO leadership on innovation in high-technology firms," The Leadership Quarterly, vol. 21, no. 1, pp. 75-88, 2010. 